CIRJE-F-775

\title{
Japan's Deflation and the Bank of \\ Japan's Experience with Non-traditional Monetary Policy
}

\author{
Kazuo Ueda \\ University of Tokyo
}

November 2010; Revised in October 2011

CIRJE Discussion Papers can be downloaded without charge from:

http://www.cirje.e.u-tokyo.ac.jp/research/03research02dp.html

Discussion Papers are a series of manuscripts in their draft form. They are not intended for circulation or distribution except as indicated by the author. For that reason Discussion Papers may not be reproduced or distributed without the written consent of the author. 
October 2011

\title{
Japan's Deflation and the Bank of Japan's Experience with Non-traditional Monetary Policy
}

\author{
Kazuo Ueda \\ Faculty of Economics \\ The University of Tokyo
}

\begin{abstract}
This paper offers a brief summary of non-traditional monetary policy measures adopted by the Bank of Japan (BOJ) during the last two decades, especially the period 1998-2006, when the so-called Zero Interest Rate Policy (ZIRP) and Quantitative Easing $(\mathrm{QE})$ were put in place. The paper begins with a typology of policies usable at low interest and inflation rates. They are: strategy (i), management of expectations about future policy rates; strategy (ii), targeted asset purchases; and strategy (iii), QE. Alternatively, QE may be decomposed into a pure attempt to inflate the central bank balance sheet, QE0, purchases of assets in dysfunctional markets, QE1, and purchases of assets to generate portfolio rebalancing, QE2. Strategy (ii), when non-sterilized, is either QE1 or QE2. Using this typology, I review the measures adopted by the BOJ and discuss evidence on the effectiveness of the measures. The broad conclusion is that strategies (i) and (ii) have affected interest rates, while no clear evidence exists so far of the effectiveness of the pure form of strategy (iii), or QE0. Strategy (ii) has been effective especially in containing risk/liquidity premiums in dysfunctional money markets; that is, QE1 has been effective. The effectiveness of QE2, however, is less clear-cut. The strategies, however, have failed to bring the Japanese economy out of the deflation trap so far. I discuss some possible reasons for this and also implications for the current U.S. situation.
\end{abstract}


The rate of change in the ex energy-food component of Japan' Consumer Price Index (henceforth, CPI) fell below zero in early 1999 and has been negative since then with only minor exceptions. The BOJ has deployed many so-called non-traditional monetary policy measures in an attempt to stop the deflation of CPI. The attempt, however, has so far not succeeded. This episode is interesting in itself, but also in light of the current disinflationary tendencies of the developed economies and central banks' attempts, especially by the Fed, to stop them. Many of the measures central banks are currently using are those that were used by the BOJ earlier. Thus, the experience of the BOJ seems to warrant a careful review.

Japan's failure to stop deflation within a short period of time must have come from one of the following three possibilities: (a) non-traditional monetary policy measures have not been as effective as some had thought; (b) the BOJ has used them in suboptimal ways; and (c) negative shocks hitting the Japanese economy have been unusually serious. I will argue in this short note that all three were playing some roles.

In section $1 \mathrm{I}$ begin with a typology of policies usable at low interest and inflation rates. In section 2 I explain the measures adopted by the BOJ, using this typology. Section 3 is devoted to the discussion of evidence on the effectiveness of the measures. In section $4 \mathrm{I}$ discuss some possible reasons for the findings and also implications for the current U.S. situation.

\section{1, Typology of Policy Options near the ZLB}

Bernanke \& Reinhart (2004) offer a convenient classification of policies near the zero lower bound on nominal interest rates (ZLB). That is, policy measures can be classified as: (i) shaping interest rate expectations or forward guidance according to Clarida (2010) — providing assurance to the market that policy rates will be lower in the future than currently expected; (ii) changing the composition of the central bank's balance sheet in a way the central bank's holdings of non-traditional assets increase (targeted asset purchases); and (iii) expanding the size of the central bank's balance sheet beyond the level required for a zero policy rate (Quantitative Easing: QE) This is summarized in Table 1.

In order to clearly differentiate between (ii) and (iii), it would be useful to think of (iii) as an attempt to expand the balance sheet by purchases of traditional assets, say, treasury bills. Then, an expansion of a central bank balance sheet based on purchases of non-traditional assets is a combination of (ii) and (iii). Strong forms of quantitative easing are accompanied by a target on a measure of central bank balance sheet or 
quantity of money.

Many central banks, in their recent pursuit of strategy (ii) since 2007, have left the funds supplied unsterilized, thus giving the appearance that they have been pursuing QE. This gives rise to an alternative typology with respect to strategies (ii) and (iii). Strategy (iii) may be regarded as plain-vanilla QE--QE0, while unsterilized version of strategy (ii) has consisted of two types: one, purchases of assets in distressed markets, QE1, and, the other, asset purchases in more normal markets, QE2. ${ }^{1}$ Another name for QE1 has been credit easing and is aimed at containment of liquidity/risk premiums in markets under stress. Asset purchases under QE2 have had the intention of generating portfolio rebalancing effects. ${ }^{2}$ This typology is also summarized in Table 1.

All these options were already suggested and discussed in the November 1999 Boston Fed conference. Since then significant amounts of works have appeared regarding the theoretical foundations of, and empirical estimates of the effectiveness of these approaches. No attempt is made here to provide a survey of the literature. (See, for example, Ueda (2012) and Curdia \& Woodford (2010).) Instead, we will focus on the Japanese experience in the remainder of the paper.

\section{2, The Bank of Japan's Monetary Policy during 1992-2006}

\section{Chronology}

Since the early 1990s the Japanese economy has experienced serious negative interactions among declining asset prices, increasingly dysfunctional financial system and deteriorating real economy. The inflation of CPI also fell below $1 \%$ by 1994 . In response to such developments the $\mathrm{BOJ}$ reduced the overnight interest rate to below $0.5 \%$ already in the summer of 1995 , from the high of $8.6 \%$ in 1991 . The economy did not recover fully despite the 800 basis point cut in the overnight rate and went into a severe credit crunch in 1997-1998. The overnight rate was lowered to virtually zero by early 1999. The inflation rate moved into negative territory in the second half of 1998 and has been there since then. Thus, the economy has been effectively in a "liquidity trap" for 15 years.

The BOJ continued its exploration for further easing measures in 1999 and the

\footnotetext{
1 The market currently seems to be using the term QE2 to mean a second round attempt at quantitative easing, which is different from, although not quite inconsistent with, the usage of the term here.

${ }^{2}$ Some of the credit easing measures that have been employed involved no purchases of assets. For example, the central bank can lend to financial institutions against distressed assets in which case this may appear just like a normal operation as far as the central bank balance sheet is concerned.
} 
2000s. The so-called zero interest rate policy (ZIRP) — the core of the BOJ's monetary policy since 1999--was introduced in April 1999. The ZIRP was not just a zero short-term interest rate, but a commitment to maintain it "until deflationary concerns were dispelled". 3

In August 2000, the BOJ lifted the ZIRP and raised the overnight call rate to $0.25 \%$ based on the judgment that the economy was recovering and showing some signs of overcoming deflation. The world economy, however, fell into a serious recession as the IT bubble collapsed in 2001, and the BOJ adopted the quantitative easing policy--let us call it QEJ, Japan's version of QE--in March 2001. QEJ consisted of three pillars. First, the BOJ maintained an ample liquidity supply by using the current account balances (CABs) at the BOJ, essentially bank reserves, as the operating policy target. Second, the BOJ committed itself to maintaining the provision of ample liquidity until the rate of change of the CPI became zero percent or higher on a sustained basis. Third, the BOJ increased the amount of purchases of Japanese Government Bonds (JGBs) from time to time as a tool for liquidity injection. It was projected that increasing the $\mathrm{CAB}$ target beyond the level of the required reserves would normally keep the call rate near zero percent. Thus, with the commitment to maintain ample liquidity provision until deflation ended, QEJ contained a version of the ZIRP. Viewed in this way, QEJ can be regarded as consisting of ZIRP and liquidity provision beyond levels necessary for a zero rate that relied partially on purchases of long-term government bonds.

The target on the CABs was increased from approximately 5 trillion yen at the introduction of QEJ in March 2001, an amount roughly 1 trillion yen greater than the then-required reserves, to a range of approximately 30-35 trillion yen in January 2004. The increases in the CABs were achieved mainly by market operations, including the BOJ's purchases of JGBs. The amount of JGB purchases was 0.4 trillion yen per month in March 2001 and was gradually increased to 1.2 trillion yen by May 2004. QEJ was finally lifted in March 2006. The extent of the BOJ's balance sheet expansion was unprecedented at that time and is comparable to that of other central banks during the late 2000s as shown in Figure 1. ${ }^{4}$

\footnotetext{
3 Some use the ZIRP to mean only a zero policy rate. Here it refers to the combination of a zero rate and the commitment to maintain it until deflation ends.

${ }^{4}$ The worldwide financial and economic turmoil that began in 2007 and the ensuing resurgence of deflationary forces in the economy have forced the BOJ to adopt various non-traditional monetary policy measures again. In October 2010 the BOJ announced a new comprehensive monetary policy package which included purchases of risky assets such as ETFs, REITs and corporate bonds as well as increased purchases of JGBs.
} 


\section{Use of the three strategies}

In terms of the classification of unconventional monetary policy measures into strategies (i)-(iii), there was first the explicit use of strategy (i) under the ZIRP and QEJ. QEJ also contained strategy (iii).

In addition, the BOJ relied on strategy (ii) extensively to contain the rise in liquidity and risk premiums in the financial system. For example, since the credit crunch of 1998, the BOJ expanded its fund-supplying operations using commercial papers (CPs) as collateral. This move is believed to have added to the liquidity of the $\mathrm{CP}$ market and, in turn, led to declines in issuing costs of CPs. In addition, the BOJ had started to accept Asset Backed Securities (ABSs) as collateral for its fund supplying operation since October 1999. In the spring of 2003 the BOJ went further by its decision to purchase Asset Backed CPs (ABCPs) and ABSs outright. Separately, the BOJ had established a standby scheme that allowed banks to sell equities they held to the BOJ since December 2002. Banks could certainly sell stocks in the market. Given the then low liquidity of the market, however, banks may have been reluctant to sell stocks and lower prices themselves.

Even operations under strategy (iii) had an element of strategy (ii). In its pursuit of QEJ, the BOJ increasingly had to lend long in the money market. This was because finding borrowers paying positive interest rate became difficult at short maturities. As of April 2001, the start of the QEJ period, fund supplying operations had maturities of one to three months. In March 2005, some operations were of 11 month maturity. In addition, to the extent that the BOJ's purchases of JGBs are regarded as targeted asset purchases, there was an extensive use of strategy (ii) during the QEJ period.

In terms of QE0-QE2, QEJ can be seen to have contained all of them. Setting the target on the current account balances formally meant that it was the amount of bank reserves that was important rather than the assets bought to achieve the target, that is, QE0 was pursued. As discussed above, however, there were also credit easing (QE1) type measures and purchases of JGBs were a core component of QEJ as well, which was QE2. All this is summarized in Table 2.

\section{3, Evidence on the Effectiveness of the BOJ's Monetary Policy}

The literature on the effectiveness of the BOJ's non-traditional monetary policy carried out during 1998-2006 seems to have found the following. ${ }^{5}$ There is evidence

\footnotetext{
5 See Ugai (2007) for a useful summary of the literature. Ueda (2012) also carries out a detailed analysis of the effects of non-conventional monetary policy measures adopted by the BOJ.
} 
that strategy (i) lowered a wide range of interest rates. The effects of QEJ are more complicated. It did lower interest rates, especially in the money market, but, apart from a small decline in the overnight rate, which was due to QE0, the declines in money market rates seem to have been a result of various QE1 type operations the BOJ carried out. There is some evidence that QE2 aspect of QEJ lowered long-term interest rates, while QE0, that is, a mere increase in the size of the BOJ balance sheet did not. Some of the measures boosted stock prices as well. Evidence on the effects on the exchange rate is hard to find. Despite the evidence of significant effects of some of the measures on interest rates, the measures obviously were not enough to stop the declines in the general price level.

Concerning strategy (i), Figure 2 shows the Euro Yen rate yield curve before and after the introduction of strategy (i) on April 13, 1999. The curve shifted down between March 2 and April 8 in response to the BOJ's attempt to lower the overnight rate down to zero. It shifted down further, however, after the announcement on April 13 to keep a zero rate until deflationary concerns dispelled. The declines can be seen to be larger for longer term rates for which expectations of future rates play larger roles. More formally, both Okina \& Shiratsuka (2004) and Oda \& Ueda (2007) show that the BOJ's commitment to maintain a zero rate until deflation ended produced strong effects on expected future short rates, thus on current medium- to long-term interest rates.

The effects of QEJ are more complicated. Figure 3 plots the movements in the 10 year swap rate and Nikkei 225 after March 2001. It can be seen that the swap rate declined and the stock market index went up sharply in response to the announcement of QEJ on March 19. This, of course, is a typical response of asset prices to a monetary easing. The stock market, with short-run ups and downs, continued to go up until early May. The cumulative increase in the index was close to $20 \%$. The 10 year interest rate turned upward after the initial decrease and rose about 35 basis points until mid-April. The combined response of the long-term interest rate and the stock market is also one possible outcome of a policy like QEJ especially if it raises growth and/or inflation expectations. Thus, QEJ did generate a successful response in the asset markets for a while. The figure shows, however, that the favorable response of the asset markets came to an end by mid-May and that both the interest rate and the stock price index came back to roughly where they were at the time of the introduction of QEJ by the end of June. The markets were disappointed by the absence of a pickup in economic activities. Thus, some asset prices did respond to QEJ favorably for a while, but not the economy. Which aspect of QEJ generated the short-run response of the asset prices requires a more careful analysis. 
As expected, money market rates did respond to QEJ on a sustained basis. For example, the weighted average of the overnight call market rate declined to a low of two basis points during the ZIRP period, but to literally $0 \%$ during the QEJ period, which probably was due to the QE0 aspect of QEJ. As a result, some banks paid negative overnight rates on certain days. More importantly, Figure 4 shows the spread between three month interbank rate and the three month Treasury bill rate. The risk premium declined during the ZIRP and QEJ periods, but slightly more in the QEJ period.

Baba et al. (2006) is an example of a more formal analysis trying to disentangle among the effects of various components of QEJ on money market rates. Using a panel data on bank negotiable certificate of deposit rates, it shows that, after controlling for the effects of changes in bank creditworthiness, the dummies for the ZIRP and QEJ periods exerted significant negative effects on the rates, while the QE0 aspect of QEJ, that is, the amount of the current account balances at the BOJ did not lower the rates. The significance of the ZIRP and QEJ dummies may be thought to indicate the effectiveness of the strategy (i) aspect of the two frameworks. The paper also shows that, for the QEJ period, the average maturity of the BOJ's fund supplying operations exerted significant effect on the rates. During the QEJ period, the BOJ had found it increasingly difficult, and thus resorted to longer and longer fund supplying operations, to hit the target on the current account balances. To the extent that the money market was still dysfunctional, these operations may be regarded as of the QE1 type, while to the extent that it was back to normal, they were of type QE2. The paper and other studies also point to the effectiveness of QE1 type operations such as CP purchases for containing risk premiums. ${ }^{6}$

Studies on the effects of the BOJ's purchases of JGBs, a QE2 type measure, on their yields have found mixed results. Oda \& Ueda (2007) fail to find any significant effects of the BOJ's purchases of JGBs on either the expected future short rates or risk premiums on JGBs. The failure may be due to the technical difficulty of separating the effects of JGB purchases from those of the commitment to maintain a zero rate. Alternatively, it could be a result of the fairly short remaining maturity of the JGBs purchased by the BOJ. ${ }^{8}$ On the other hand, Bernanke, Reinhart and Sack (2004), who carry out a macro finance analysis of the ZIRP and QEJ, find statistically significant links between the BOJ's purchases of JGBs and JGB yields.

\footnotetext{
6 See, for example, the BOJ (2009).

7 The remaining maturity of JGBs bought by the BOJ declined to less than 4 years in 2005. See McCauley and Ueda (2009).

${ }^{8}$ Several recent studies of the effect of the Fed's purchases of government bonds have found significant effects on interest rates. See, for example, Gagnon, Raskin, Remache and Sack (2010) .
} 
Ueda (2012) carries out a detailed analysis of almost all policy measures adopted by the BOJ on asset prices, including stock prices, short- to long-term interest rates and exchange rates. It finds that most of the easing measures led to declines in interest rates and a rise in the stock market. However, the effects of QE0 type moves, that is, increases in the target for the current account balances without accompanying increases in the amount of JGB purchases or other targeted asset purchases, are found to be statistically insignificant. This result points to the effectiveness of QE1 and/or QE2. The study, however, does not find significant effects of the measures on the exchange rate.

There were at least two more significant monetary policy measures adopted that seem to fall under the heading of strategy (ii), the BOJ's purchases of equities from banks (2002-2004) and purchases of ABS (2003-2005). ${ }^{9}$ The purchases of ABS were not very successful mainly because the market for ABS was still very small. Against the ceiling of 1 trillion yen, the outstanding amount of the ABS held by the BOJ in 2005 was only 0.12 trillion. "Credit easing" seems to be effective only when there is a large market which experiences a major disruption, say, a significant decline in market liquidity. On the other hand, the BOJ ended up buying roughly the targeted amount, 2 trillion yen in its equity buying scheme. This operation may be seen as an attempt to address a temporary decline in the stock market liquidity and the erosion of bank capital as stock prices plummeted. A more rigorous evaluation of this scheme, however, is a topic for future study. ${ }^{10}$

To summarize, there is evidence that strategy (i) and some of strategy (ii) affected asset prices, especially, interest rates and stock prices, but the evidence for the effectiveness of strategy (iii) is weak.

\section{4, Discussion}

\section{Some difficulties with Strategy (i)}

The above discussion points to the effectiveness of strategy (i) for generating easing effects. Some of the problems of the strategy, however, need to be noted. First, it is well known that the strategy suffers from dynamic inconsistency problems. It essentially commits to the continuation of monetary easing even after it becomes unnecessary. Hence, there is an ex post incentive to renege on the promise made.

\footnotetext{
${ }^{9}$ Purchases of equities were explicitly sterilized. That is, they were carried out as strategy (ii). On the other hand, those of ABS were a part of QEJ.

10 Ueda (2012) finds some effect of the equity purchase scheme on the stock market. It also studies, and finds significant effects of some of, the easing measures adopted since 2008.
} 
Second, a more practical problem faced by the BOJ was the following. The strategy did lower interest rates to some extent, but did not succeed in raising prices. The absence of quick fruits invited calls for further action from outside. This strategy, however, does not easily lend itself to use in an incremental manner. For example, one can think of revising "continuation of a zero rate until deflation ends" into "continuation of a zero rate until inflation is one percent." There is, however, an obvious limit. Moreover, if a stronger commitment was useful, it should have been put to use in the first place. Thus, with the use of the strategy the central bank is apt to experience a painful period in which the only thing it can do is to prey for an increase in the natural rate of interest.

\section{Foreign exchange market intervention and non-traditional monetary policy}

Normally, foreign exchange market intervention (henceforth, intervention) is more powerful when accompanied by a monetary policy change. This general principle has led to enormous confusion about intervention at the ZLB. Regarding Japan's intervention, especially since 1999, many argued that it would not affect the exchange rate if it was sterilized.

A short comment on the institutional aspect of intervention is in order. In Japan's case an intervention to purchase a foreign currency is a decision made by the Ministry of Finance (MOF). The MOF finances this operation by a temporary sale of treasury bills to the BOJ, which is understood to be undone by a prompt issuance of treasury bills in the market. The BOJ normally "sterilizes" the fund flows generated by intervention. ${ }^{11}$ Otherwise, the overnight interest rate will be affected. This certainly implies that if the funds were left un-sterilized, monetary policy is eased and a larger effect on the exchange rate can be expected.

At the ZLB, the difference between unsterilized and sterilized intervention is an expansion of central bank balance sheet by a purchase of treasury bills, which is QE0. To the extent that QE0 is ineffective at the ZLB, the difference between the two types of intervention is nil. Needless to say, the difference can be non-negligible if the BOJ sterilizes the initial intervention, but embarks on a certain type of QE1 or QE2 that is expected to generate some easing effects on the economy.

One unexpected outcome of QE0 or QEJ, however, was that the U.S. Treasury seems to have given a green light for Japan's intervention to the extent that it was

\footnotetext{
${ }^{11}$ In practice, the BOJ compares the fund generated by intervention along with other supply of funds in the system and the level of funds consistent with the target on the overnight rate, and decides on the amount of fund supplying/withdrawing operations.
} 
unsterilized. ${ }^{12}$ Japan carried out huge amounts of U.S. dollar purchasing interventions in the early 2000s, which may have been a factor behind the tendency for the U.S. dollar to stay above 100 yen during the period. If this claim that the interventions were made possible by QEJ is correct, QEJ or QE0 had the "unintentional" consequence of making possible the MOF's intervention, which is use of strategy (ii) by the MOF, and moderated the deflationary pressure in the economy.

\section{Financial crisis, other deflationary forces and the BOJ policy}

The summary of evidence on the effectiveness of non-traditional monetary policy measures in the last section indicated that while some of the QE1 type measures were effective, evidence on the effectiveness of QE2 type measures was less clear. This seems to place central banks in a difficult situation if a major financial crisis forces them to lower interest rates to near zero levels and adopt non-traditional policies, but deflationary concerns remained even after financial stresses dissipated. This is because the room for further use of QE1 measures would narrow, while QE2 measures may not be very effective.

In a sense the BOJ was in such a situation in the mid 2000s. Serious stresses in the money market disappeared, but banks were still not lending. CPI inflation became positive only because of rising commodity prices, while its ex food and energy component stayed in negative territory. As the financial system stabilized, it became difficult for the BOJ to find strategy (ii) (QE1) type measures to adopt. QE2 was not producing clear-cut effects.

Strong deflationary forces remained in the Japanese economy through the mid 2000s. Not only banks but also non-financial corporations were in a serious de-leveraging mode. The non-financial corporate sector saw a sharp, unintended rise in leverage in the 1990s as a result of declining asset prices. This forced them to go through a long period of de-leveraging by using savings to repay debt. Additionally, fiscal policy has been tight especially since 2000. The declining population also added to the weakness in aggregate demand for goods and services. These forces seem to have limited the impact of the BOJ's operations on the economy.

We might add that although inflation fell into negative territory, it did not show a tendency for a deflationary spiral, which is somewhat of a puzzle. It may well be that the BOJ's non-traditional policy measures have had at least the positive effect of avoiding a destabilizing rise in the rate of deflation.

12 See Taylor (2007), pp. 284-87. 


\section{Could the BOJ have done more?}

In light of the BOJ's failure to stop deflation, one might argue that the BOJ should have done more. Regarding strategy (ii), the BOJ may have taken larger credit or market risks. This could have included purchases of bank loans, direct lending by the BOJ or taking properties as collateral. The BOJ can hardly be seen, however, to have comparative advantage in these activities. Also, some of these operations are fiscal policy in nature. Either, they should be done by the government or there needs to be an accord between the BOJ and the government about the purpose, size, and loss sharing rule of the operations if the BOJ's balance sheet is to be used. Similarly, the BOJ could have bought more JGBs. Again, this would have also called for a BOJ-government accord on possible loss sharing. In addition, strategy (i) could have been strengthened to, for example, "continuation of a zero rate until inflation reached 1\%." Or else, some version of price level targeting could have been adopted.

Ten year JGB rates had been, however, in the range of $0.5-2.0 \%$ for most of the period. This was a joint result of the BOJ's unconventional policy measures and, ironically, their failure to increase inflation and inflation expectations. It is unclear by how much, if any, rates would have declined by much larger purchases by the BOJ and by how much possible declines in rates would have been stimulated the economy. What seems to have been necessary was a rise in inflation expectations or an expectation of a sustained pickup in economic activity. Such changes in expectations were unfortunately observed only for a brief period right after the introduction of QEJ as we saw in Figure 3.

\section{Should the BOJ have acted earlier? Implications for the U.S.}

Raising actual and expected inflation does not seem to be an easy task once deflationary expectations become entrenched. From this perspective non-traditional monetary policy measures by the BOJ may have come slightly too late. Figure 5 shows CPI inflation rates after the peak of the bubble in Japan and the U.S with the left end of the horizontal axis set to equal the peak of the bubble, the beginning of 1990 for Japan and the summer of 2007 for the U.S. As argued above, inflation was already below $1 \%$ in Japan in the mid 1990s. Adoption of, say, strategy (i) around that time may have had a higher chance of success. ${ }^{13}$ In reality, the BOJ adopted strategy (i) in 1999 when inflation was already negative.

This line of reasoning suggests that the U.S. economy may be at a critical point.

\footnotetext{
13 In addition, policies to address the bad loan problem of the banking sector, especially the recapitalization of banks, should have come much earlier.
} 
Some non-traditional measures, especially QE1, have been used and successfully contained financial market stresses. But the risk of further disinflation remains. Figure 5 shows that U.S. inflation is now close to where Japanese inflation was in the mid 1990s. Limitations of the effectiveness of further non-traditional measures cannot be ignored. For example, with resumption of stability in financial markets central banks will have to shift from QE1 to QE2 type measures whose effectiveness is less certain. The measures may succeed in lowering interest rates further. Figure 6, however, shows 5 year swap rates for both Japan and the U.S. The rate in the U.S. is already close to where Japan's rate was at the beginning of the ZIRP period. The room for further declines in interest rates is limited. It is quite uncertain by how much further monetary policy measures will stimulate the U.S. economy.

\section{Issues concerning the exit from non-traditional measures}

On the other hand, a reversal of the disinflationary trend will prompt attempts to exit from non-traditional monetary easing policies. Below I offer a few remarks about the BOJ' experience in this regard.

The BOJ decided to exit from QEJ in March 2006. Figure 7 shows that within half a year the current account balances declined by more than two thirds. The figure also shows that these declines in the current account balances were matched by reductions in the outstanding amount of short-term fund supplying operations. That is to say, the BOJ did not roll over short-term fund supplying operations and reduced the amount of funds in the system. Thus, the process of reductions in the size of the balance sheet was smooth in the BOJ's case as it had large amounts of short-term fund supplying operations at the time of exit. ${ }^{14}$ This may not be the case for other central banks, although they can, of course, tighten by raising the interest rate on (excess) reserves.

In contrast to the current account balances, reducing the amount of JGB purchases or selling the equities purchased was not easy for the BOJ as shown in Figures 8 and 9. The BOJ has never sold the JGBs it purchased. In fact, it had continued to buy the same amount of JGBs as in the QEJ period even after the exit until it increased the amount of purchases in response to the recent worldwide financial crisis. There is some decline in the amount of equities the BOJ holds, but most of the decline has come from valuation effects. ${ }^{15}$ Relationships with the fiscal authority may have mattered for the decision to keep the amount of JGB purchases the same even after the exit, while possible market

14 It is also noteworthy that these sharp declines in the current account balances did not produce serious negative effects on the economy. This is consistent with weak effects of QE0 on the economy.

15 The BOJ has been buying equities again in response to the recent financial and economic crisis. 
impact may have slowed the pace of the BOJ's sale of equities it purchased. Such an experience of the BOJ suggests possible difficulties of exit from large scale purchases of non-traditional assets.

\section{References}

Baba, Naohiko, Motoharu Nakashima, Yosuke Shigemi \& Kazuo Ueda (2006) "The Bank of Japan's Monetary Policy and Bank Risk Premiums in the Money Market," International Journal of Central Banking, Vol. 2, No.1, March.

Bank of Japan (2009) Financial Markets Report, Financial Markets Department, August 31.

Bernanke, Ben. S. \& Vincent R. Reinhart (2004), "Conducting Monetary Policy at Very Low Short-Term Interest Rates," American Economic Review, Vol. 94, No. 2.

— — \& Brian P. Sack (2004), "Monetary Policy Alternatives at the Zero Bound: An Empirical Assessment," Brookings Papers on Economic Activity, 2:2004, pp. 1-78.

Bryant, Ralph C. (2000) "Comment on the Goodfriend paper," Journal of Money, Credit and Banking, Vo. 32, No.4.

Clarida, Richard. (2010) "What Has--and Has Not--Been Learned about Monetary Policy in a Low Inflation Environment? A Review of the 2000s," paper presented at the Federal Reserve Bank of Boston 55th Economic Conference, October 14-16.

Curdia, Vasco. \& Michael Woodford (2010) "The Central-Bank Balance Sheet as an Instrument of Monetary Policy," paper presented at the 75th Carnegie-Rochester Conference on Public Policy, April 16-17.

Gagnon, Joseph, Matthew Raskin, Julie Remache and Brian Sack (2010) "Large Scale Asset Purchases by the Federal Reserve: Did They Work?" Federal Reserve Bank of New York Staff Report 441.

McCauley, Robert N. \& Kazuo Ueda (2009) “Government Debt Management at Low Interest Rates,” BIS Quarterly Review, June.

Oda, Nobuyuki \& Kazuo Ueda (2007) “The Effects of the Bank of Japan's Zero Interest Rate Commitment and Quantitative Monetary Easing on the Yield Curve: A Macro-Finance Approach," The Japanese Economic Review, Vo. 58, No.3, September.

Okina, Kunio \& Shigenori Shiratsuka (2004) "Policy Commitment and Expectation Formation:Japan's Experience under Zero Interest Rates," North American 
Journal of Economics and Finance, Vol. 15, No.1.

Taylor, John (2007) Global Financial Warriors, W. W. Norton \& Company, Inc. NY, NY. Ueda, Kazuo (2012) “How Effective Have the BOJ's Non-traditional Monetary Policy

Measures Been?" Japanese Economic Review, Vol. 63, No.1, March.

Ugai, H. (2007) "Effects of the Quantitative Easing Policy: A Survey of Empirical Analysis," Monetary and Economic Studies, Vo.25, No.1, Bank of Japan.

Table 1 Policy Options near the ZLB

\begin{tabular}{|l|l|l|}
\hline Strategy i & managing expectations about future levels of the policy rate & \\
\hline intended effect & today's medium- and long-term rates will be affected & \\
\hline Strategy ii & targeted asset purchases & \\
\hline & (may include lending against non-traditional assets) & without \\
intended effect & portfolio rebalancing & sterilization \\
\hline & liquidity premiums in dysfunctional markets will be reduced & QE2 \\
\hline & & QE1 \\
\hline Strategy iii & Quantitative Easing (purchase TBs to raise excess reserves) & \\
\hline intended effect & inflation expectations may rise? & QE0 \\
\hline & & \\
\hline
\end{tabular}

Table 2 The BOJ's Non-traditional Operations during 1999-2006

\begin{tabular}{|l|l|l|}
\hline Strategy i & $\begin{array}{l}\text { zero rate until deflationary concerns are dispelled (April 1999-August 2000) } \\
\text { zero rate until CPI inflation becomes stably above zero (March 2001-March 2006) }\end{array}$ \\
\hline Strategy ii & purchases of equities from banks & \\
\cline { 2 - 3 } & $\begin{array}{l}\text { unusually long-dated fund supplying operations } \\
\text { CP repo } \\
\text { purchases of ABCP/ABS }\end{array}$ & QE1 \\
\cline { 2 - 3 } & purchases of JGBs & QE2 \\
\hline Strategy iii & Quantitative Easing (target on the banks' current account balances) & QE0 \\
\hline
\end{tabular}




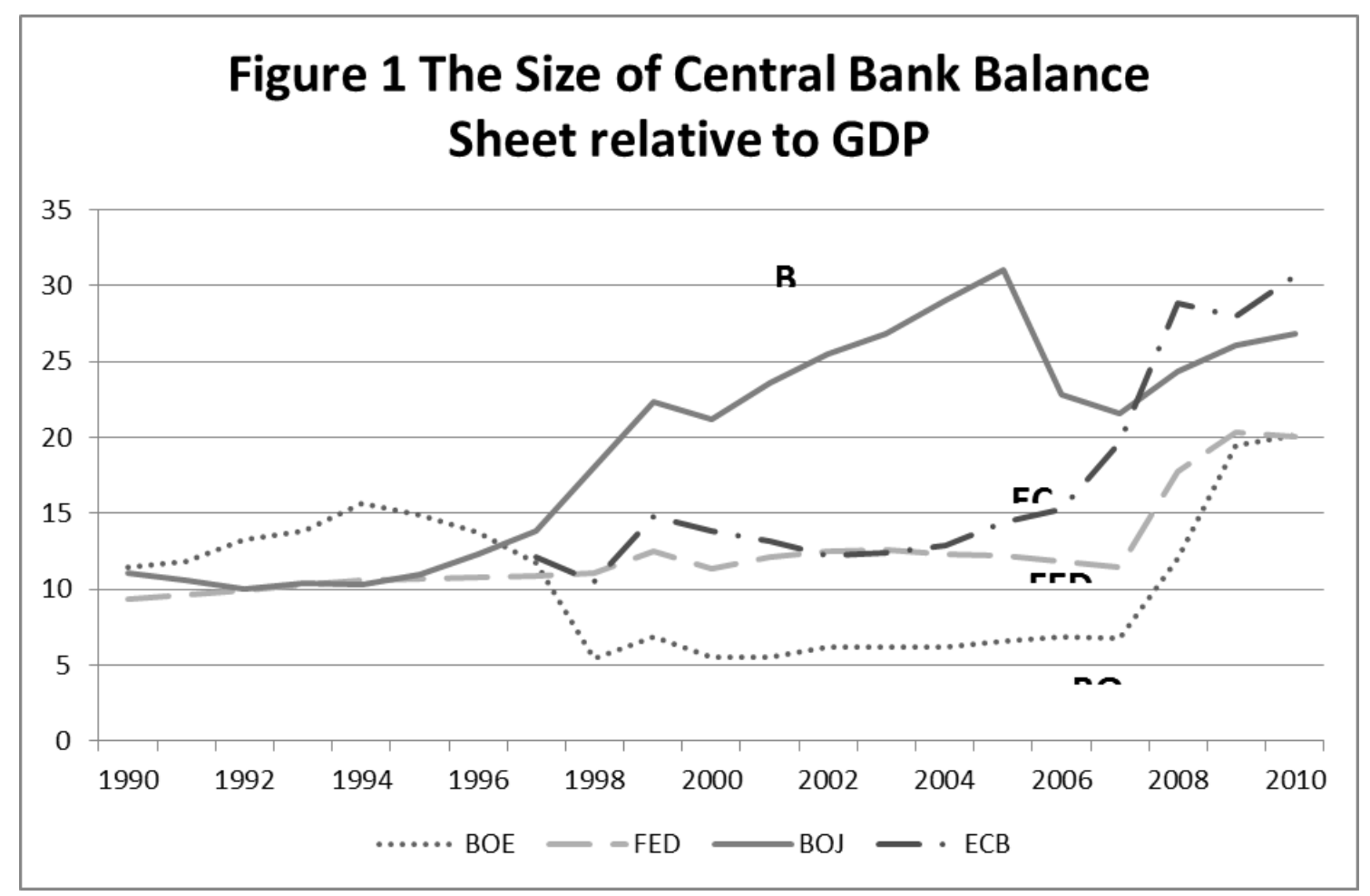

Data source: CEIC. 


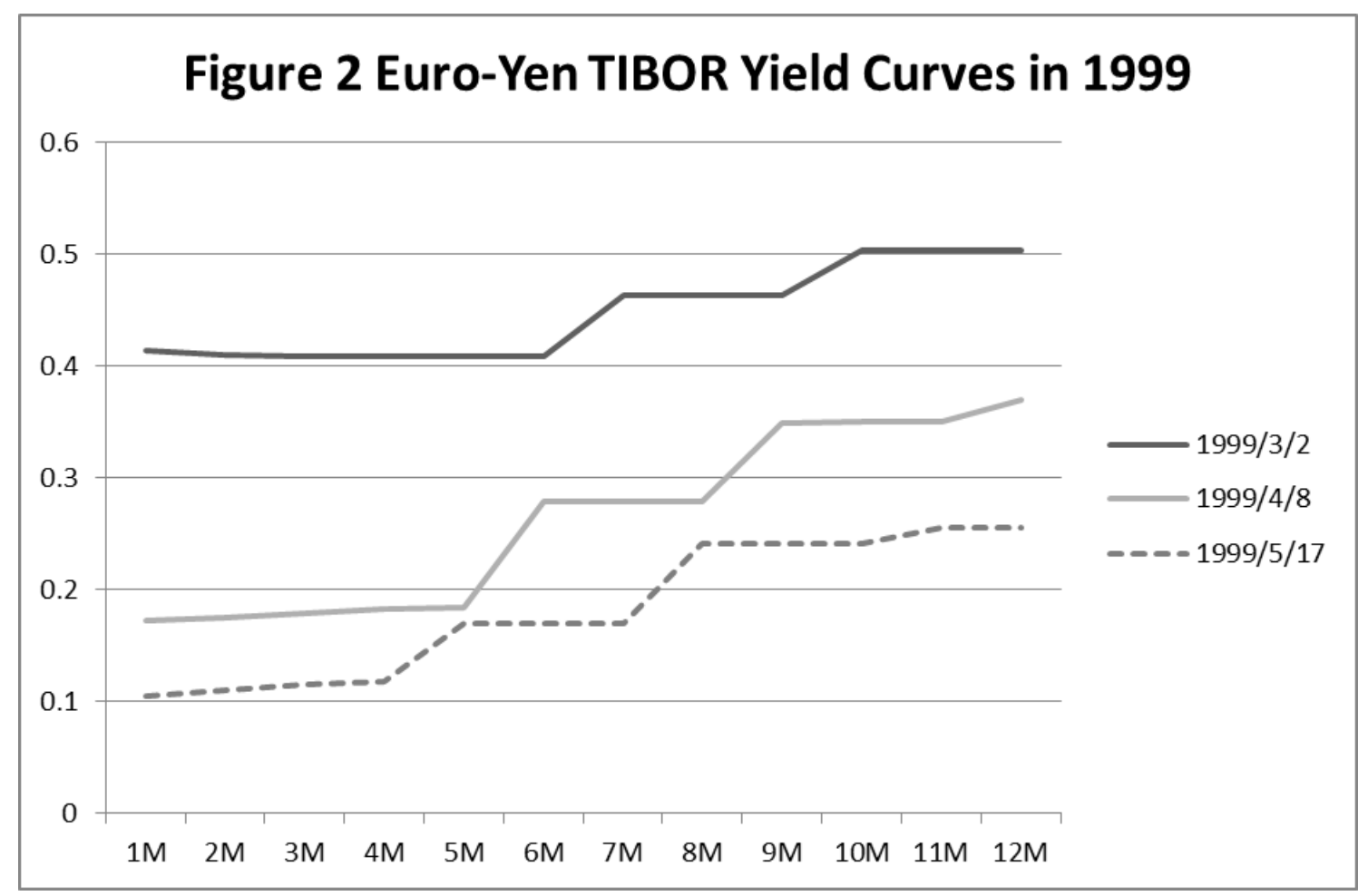

Data source: Bloomberg. 


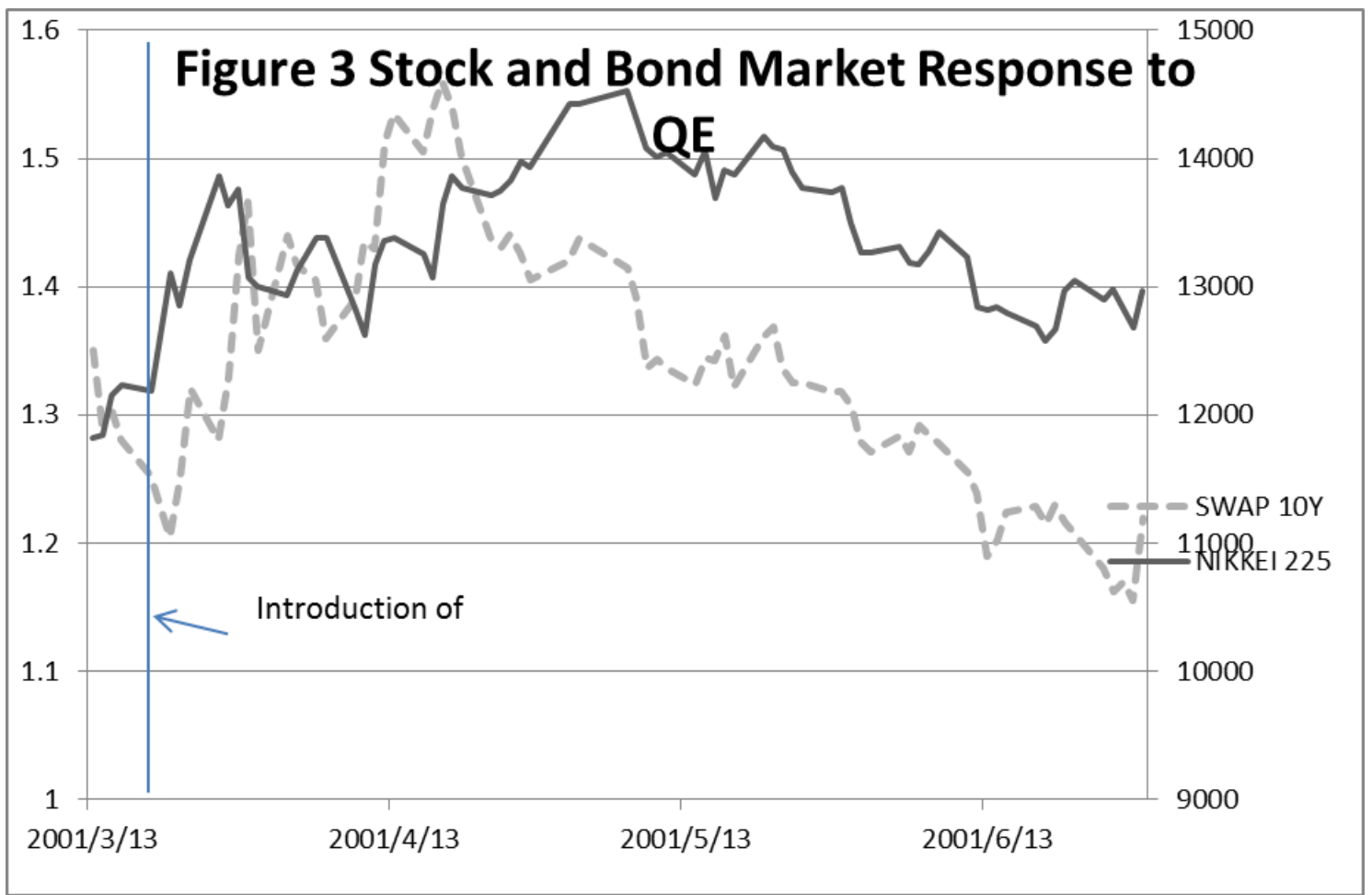

Data source: Bloomberg. 


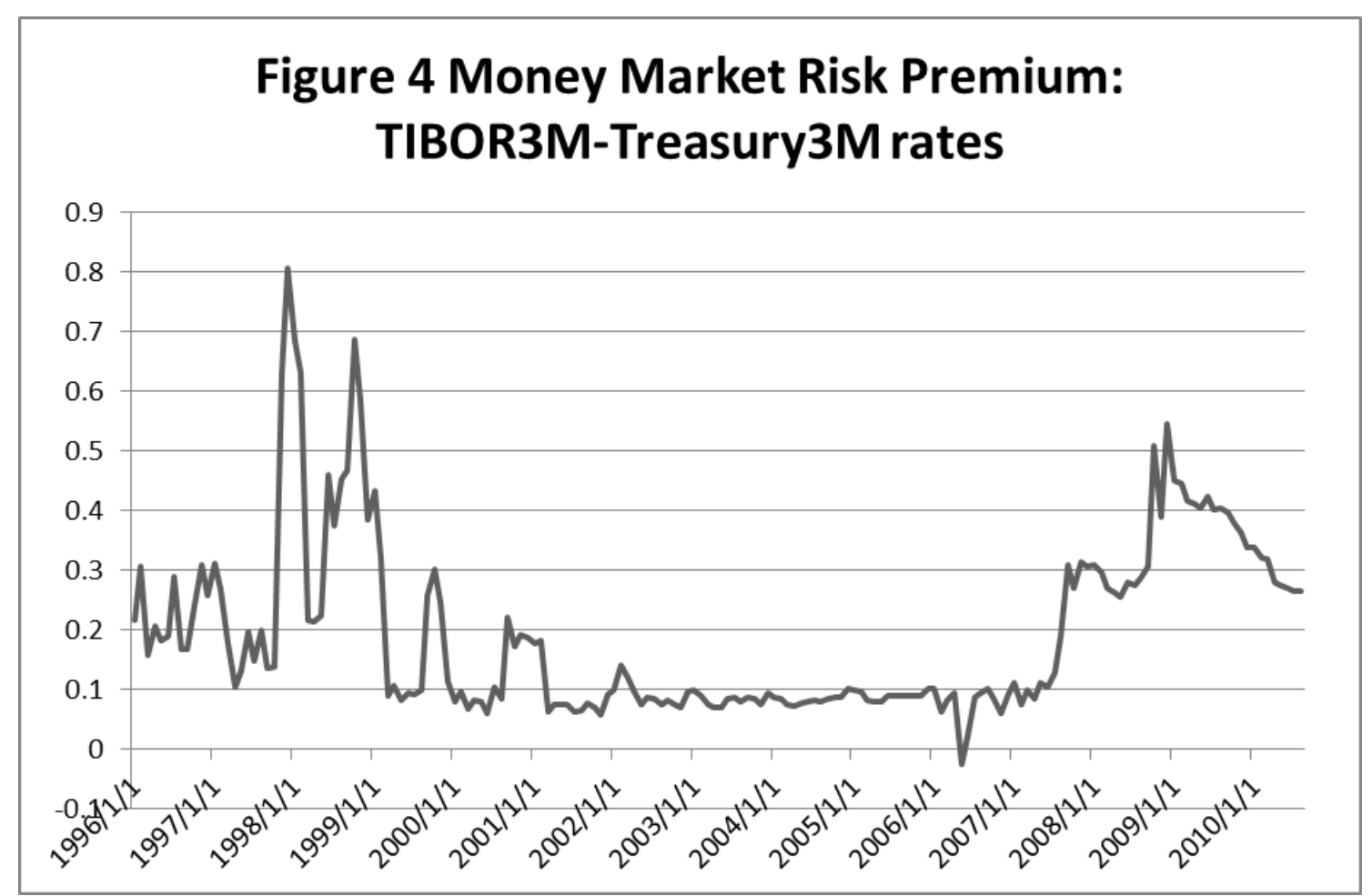

Data source: Bloomberg. 


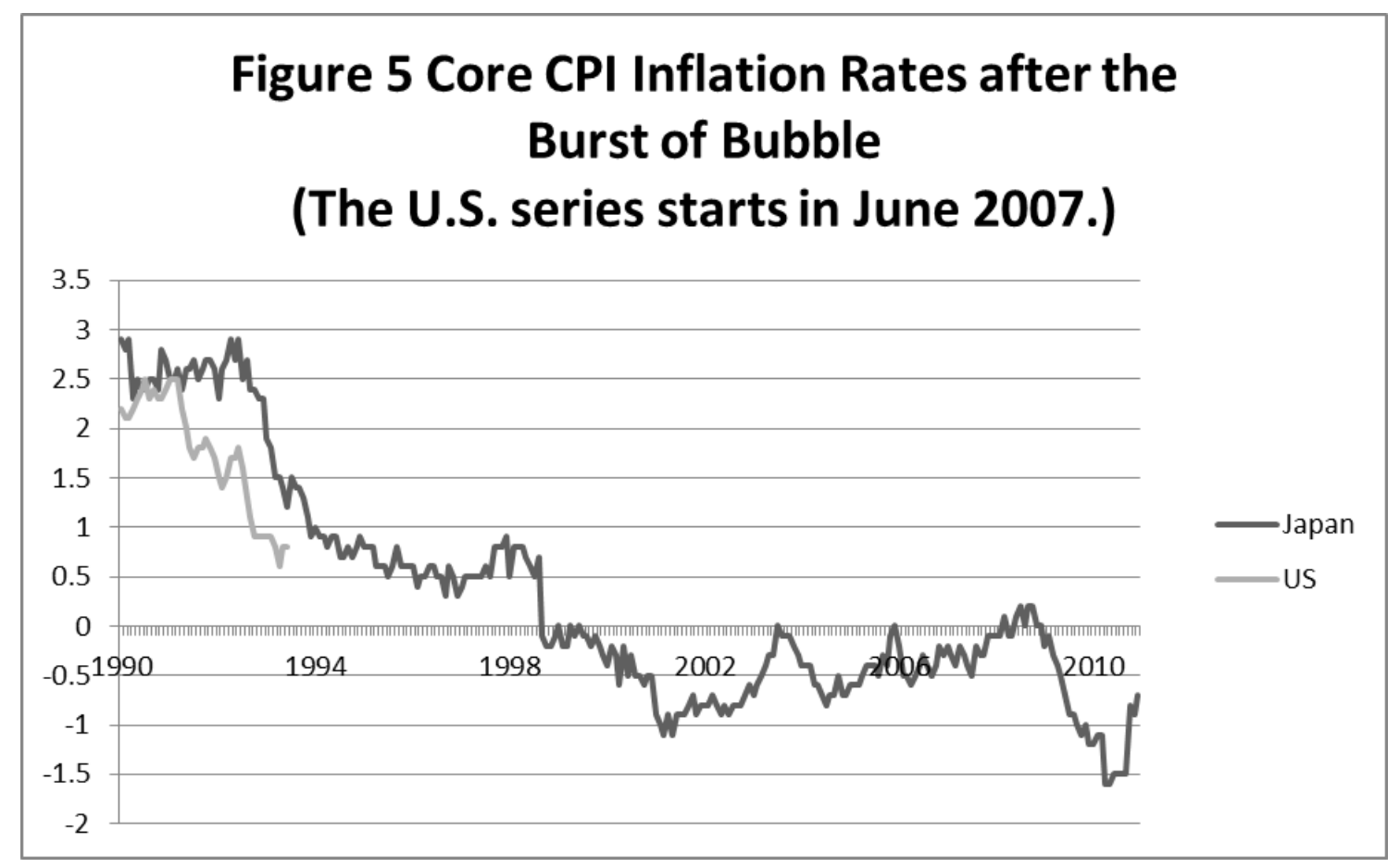

Datasource: Datastream. 


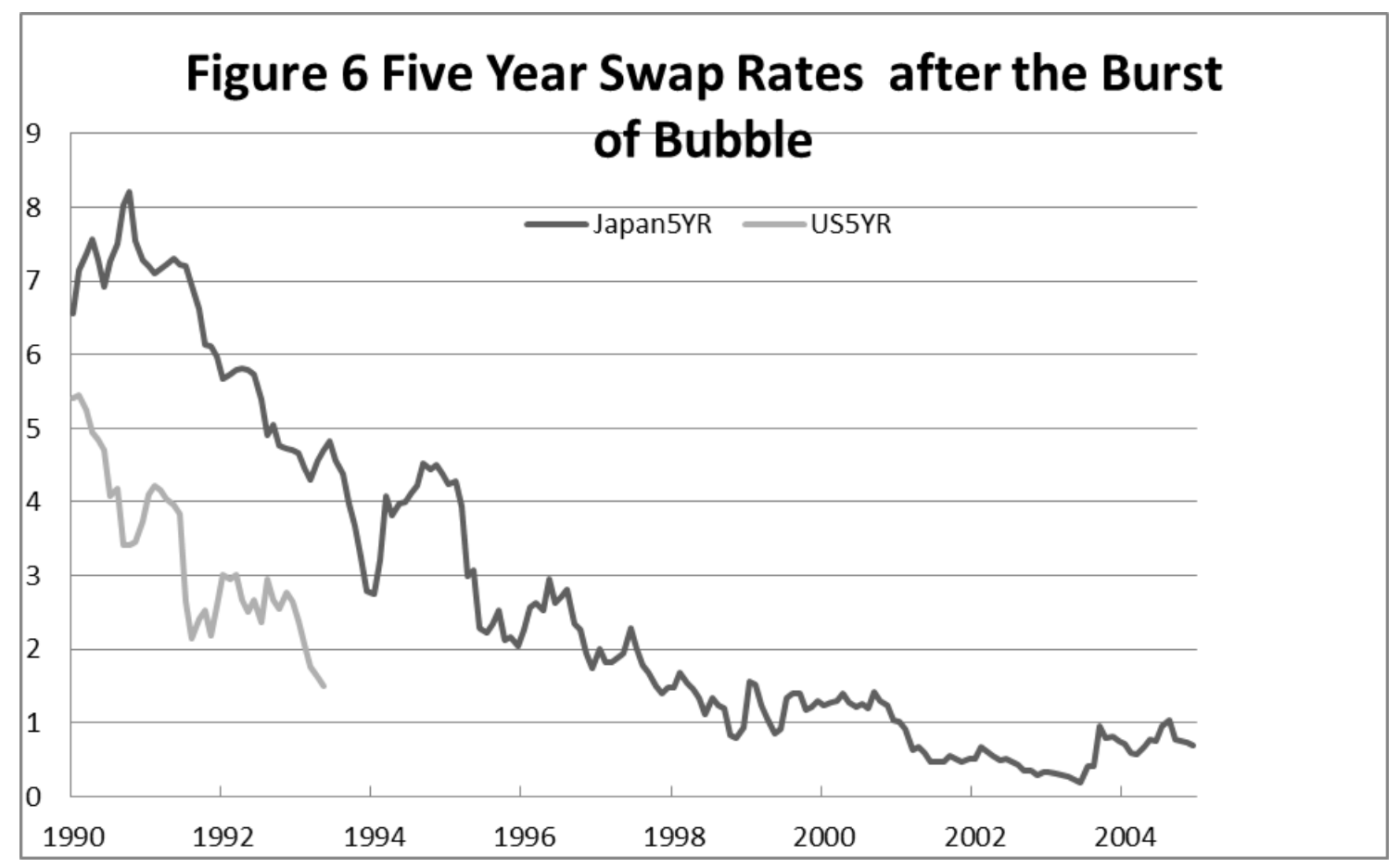

Data source: Bloomberg. 


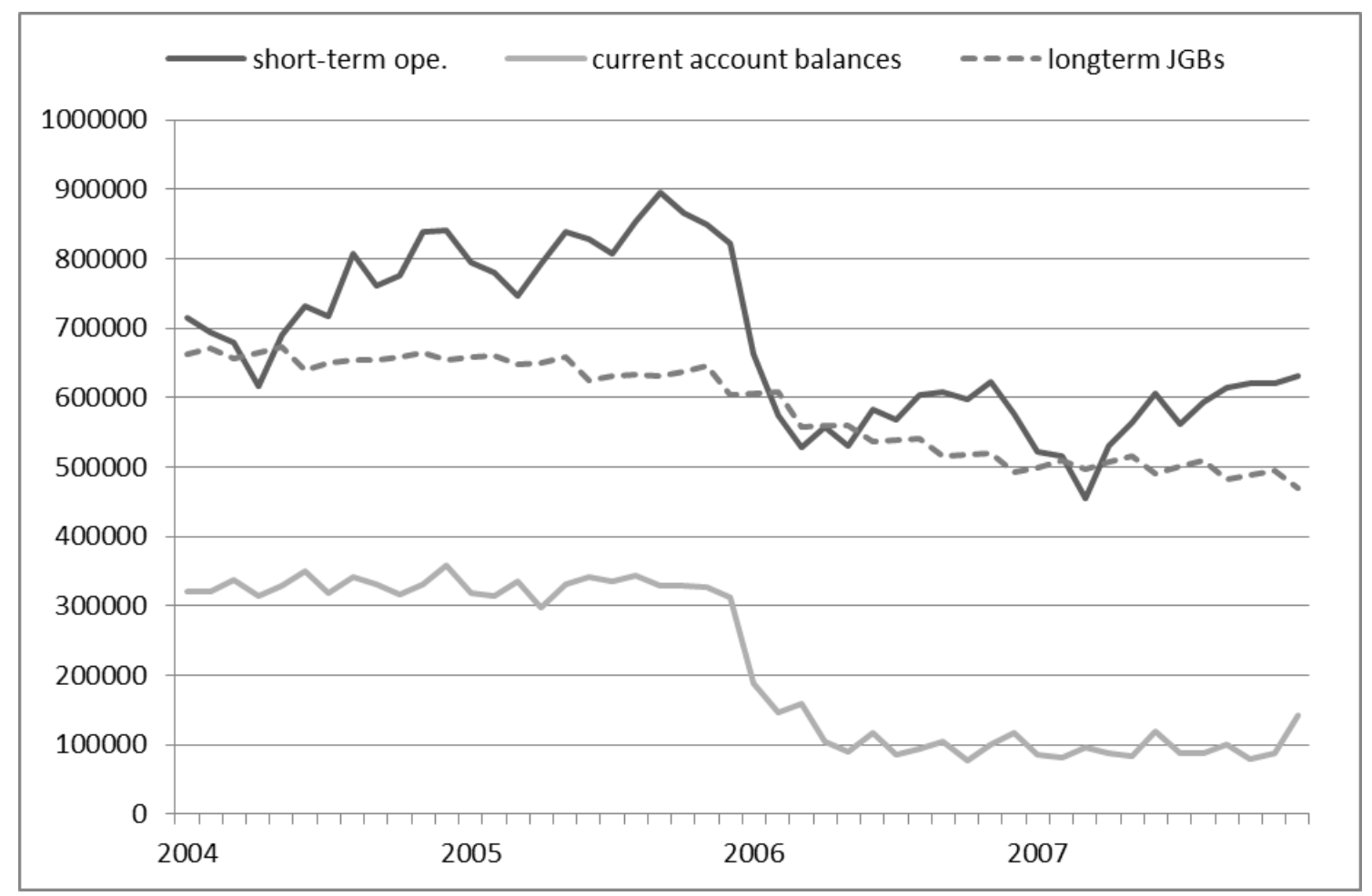

Figure 7 The BOJ's Exit from QE (data source: CEIC) 


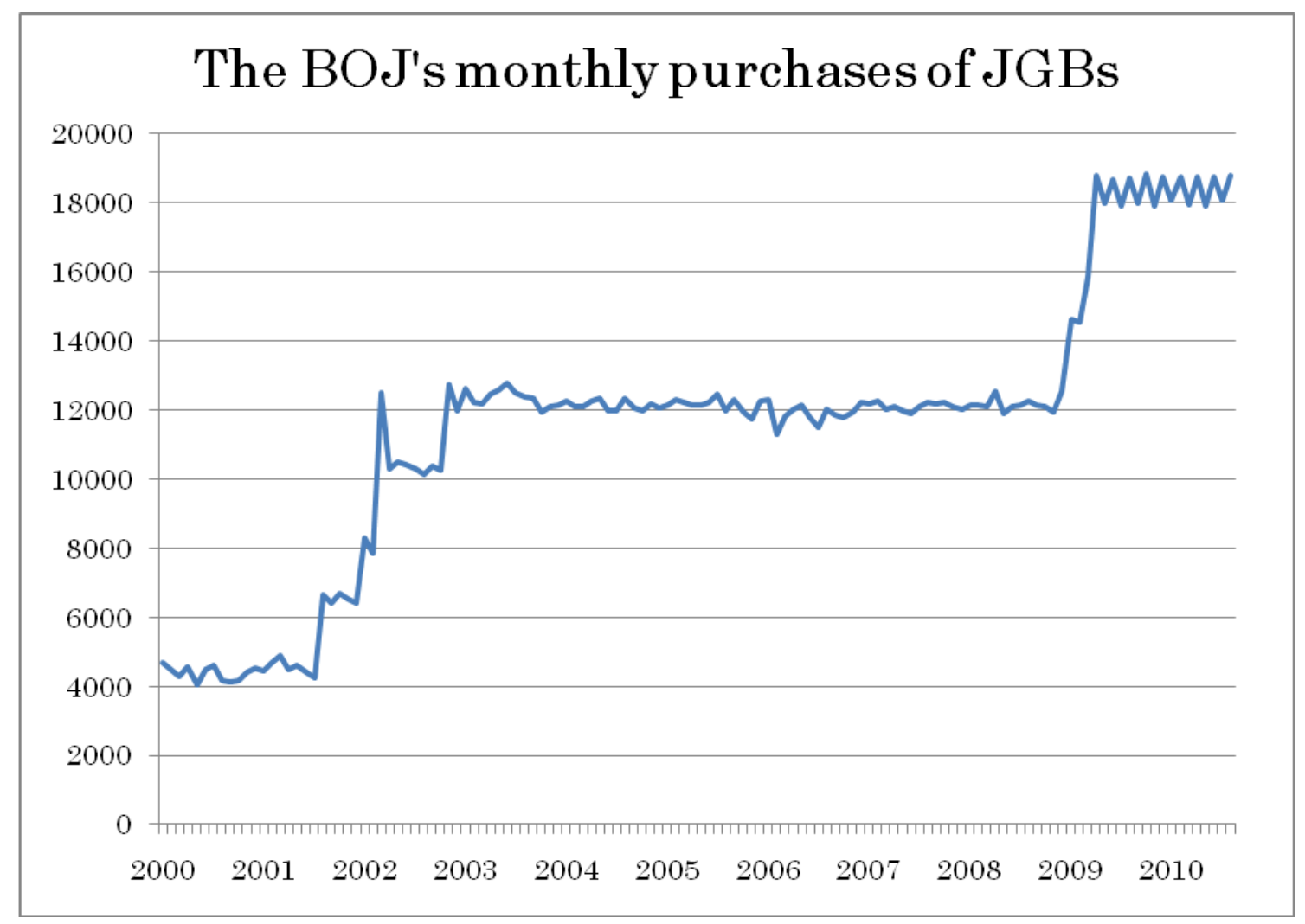

Figure8 The amount of the BOJ's Monthly Purchases of JGBs (data source: CEIC) 


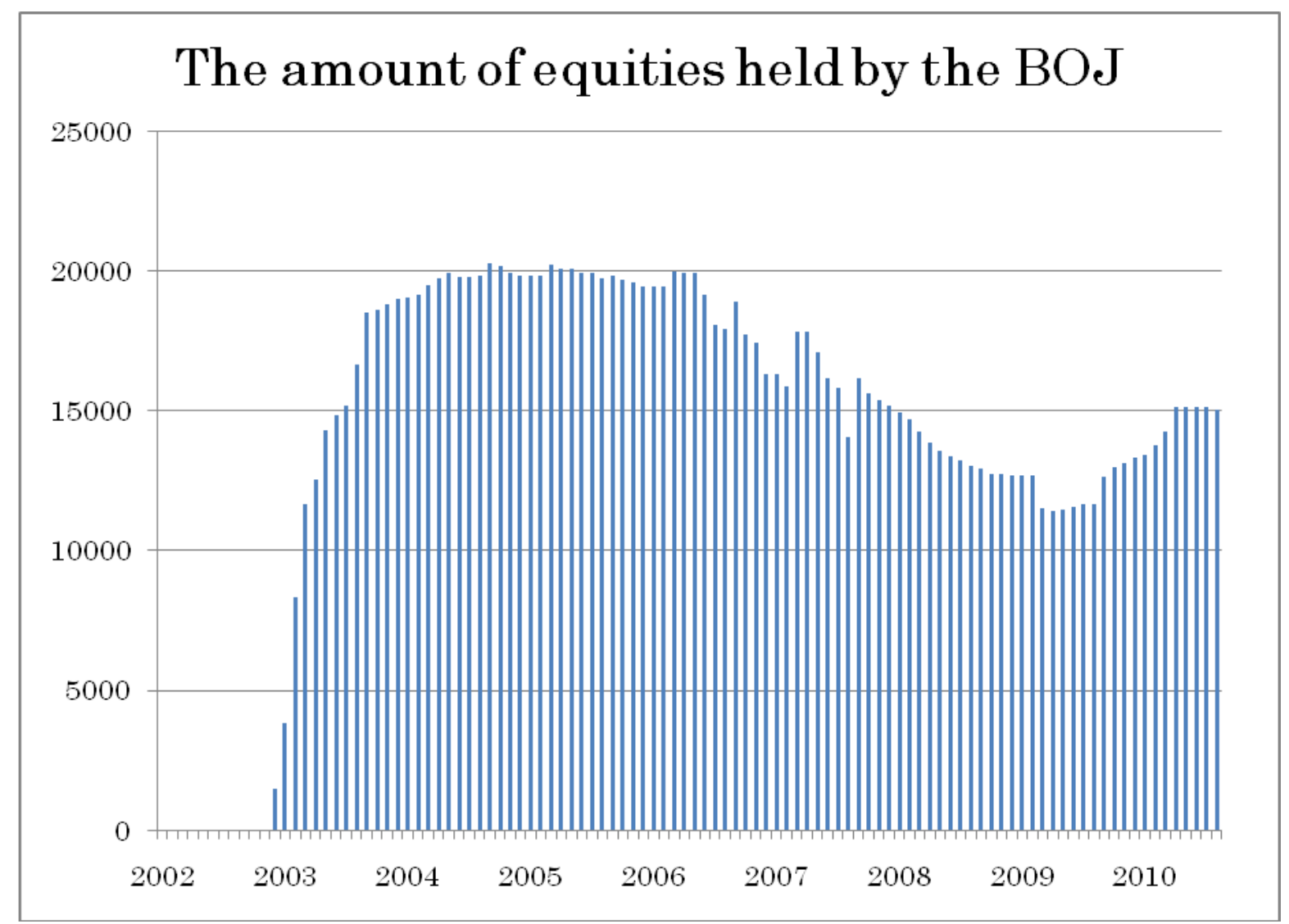

Figure 9 The amount of equities held by the BOJ (data source: CEIC) 